\title{
Beneficial effects of vestibular stimulation on learning and memory: an overview
}

\section{Editorial}

The vestibular system is considered the entryway to the brain and is said to have the most important influence for everyday functioning. Recent studies underlines the function of vestibular system is not just maintaining balance and equilibrium or reflexes but beneficial in advanced functions like improving cognition, improving diabetic condition, reducing stress etc. As the vestibular system remains enigmatic among the human senses it is fast becoming one of the most thoroughly and broadly researching topic. ${ }^{1}$ Stimulating vestibular system in a controlled way has shown many benefits like decreased self-stimulation, decreased hypersensitivity, increased postural security, increased concentration and attentiveness, increased balance, increased body awareness, calming effects, reduction of abnormal muscle tone. ${ }^{2}$ Although cradles, which apply a basic form of

passive vestibular stimulation, have existed for a very long time ago to develop various strategies to achieve vestibular stimulation have started in $17^{\text {th }}$ century. Ancient Greek and Roman physicians used motion devices to calm, soothe and even cure people. ${ }^{3}$ Various motion devices, like hanging beds, conventional swings, rotating chairs and rotating beds were used for vestibular stimulation and later in $18^{\text {th }}$ century reappeared in the name of famous scientists like Cox's chair or Hallaran's swing. ${ }^{4,5}$ Day today life vestibular stimulation can be achieved by activities like jogging, jumping (in a trampoline), playing marry go rounds (rotatory stimulation), swinging (linear stimulation), dancing. Experimentally vestibular system can stimulate by placing surface electrodes on mastoid process i.e. stimulating the vestibular nerve. This method is called Galvanic Vestibular Stimulation. Caloric Vestibular Stimulation is a method using cold/hot water/air against the tympanic membrane to stimulate current in the endolymph of the vestibular organs. ${ }^{7}$ Vestibular stimulation is also achieved by rotational and linear motion devices. ${ }^{89}$ Magnetic and infrared vestibular stimulation are the new advanced techniques in vestibular research. ${ }^{10,11}$

Several reports suggested that spatial learning deficits in animals and humans after vestibular lesions or loss. It has been found that head direction cells' in the anterior thalamic nuclei ${ }^{12}$ and location-related firing of 'place cells' in the hippocampus was abolished in rats after bilateral labyrinthectomy. ${ }^{13,14}$ Neuronal tracers, electrophysiology, immuno- histochemistry, functional imaging and also indirectly through behavioural studies in animals and humans has revealed that the vestibular system is massively connected to the cognitive areas of the brain like hippocampus and parahippocampal region, parietoinsular vestibular cortex (PIVC), anterior parietal cortex, posterior parietal and medial superior temporal cortices, cingulated gyrus and retrosplenial cortical regions. ${ }^{15}$ Place cells (important for identifying specific location, time representation of the past (spatial memory) and the future (navigational planning) and Head Direction cells (HD cells) are direction specific cells essential to navigate without landmarks (e.g., an unknown environment) are two categories of cells are mainly influenced by vestibular inputs. ${ }^{16}$ So vestibular atrophy primarily affects these cells and impairs the generation of theta rhythm by place cells. ${ }^{17}$ Patients with chronic bilateral vestibular deficits suffers bilateral hippocampal atrophy and spatial memory impairment. vestibular stimulation enhances Long Term Potentiation (LTP) in

\author{
Volume 5 Issue 3 - 2018
}

\author{
Kumar Sai Sailesh,' Ravikanth Manyam, ${ }^{2}$ Jinu \\ $\mathrm{KV},{ }^{3}$ Archana $\mathrm{R}^{4}$ \\ 'Department of Physiology,Vishnu Dental College, India \\ 2Department of Oral Pathology, Vishnu Dental College, India \\ ${ }^{3}$ Research Scholar, Saveetha University, India \\ ${ }^{4}$ Department of Physiology, Saveetha University, India
}

Correspondence: Sai Sailesh Kumar G,Assistant Professor, Department of Physiology, Vishnu Dental College, Bhimavaram, Andhra Pradesh, India, Email dr.saisailesh@gmail.com

Received: May 28, 2018| Published: June 07, 2018

CA1 area of hippocampus especially by activating septohippocampal cells and causes long-lasting increase in synaptic transmission of Ach. ${ }^{18}$ As the decrement of Serotonin and brain derived neurotrophic factors strongly affected in the regulation of synaptic plasticity and neurogenesis, various experiments have proven that vestibular stimulation is beneficial in increasing serotonin level in brain. ${ }^{19}$ Another study has proven that rotatory vestibular stimulation increase in the dendritic arborization and synapses in the hippocampal pyramidal neurones which improves the performance in the spatial learning tasks. Vestibular stimulation not only increases Ach level but decreases the AchE activity. ${ }^{19}$ Vestibular stimulation inhibits HPA and SAM axis so create a stress less condition which modulates learning and memory. ${ }^{20}$

Even though the effectiveness of vestibular stimulation in improving learning and memory reported in various studies, the extent of beneficial effects in dementia are not deeply explored. Hence, large scale studies are recommended to ensure the effectiveness and therapeutic effects of vestibular stimulation in dementia.

\section{Acknowledgements}

None.

\section{Conflict of interest}

The author declares no conflict of interest.

\section{References}

1. Smith PF, Zheng Y. From ear to uncertainty: vestibular contributions to cognitive function. Front Integr Neurosci. 2013;7:84.

2. Sailesh KS, Mukkadan JK. Can controlled vestibular stimulation reduce stress-a review. Health sciences. 2013;2(3):js00.

3. Jütte R. Schwindelerregend: Drehmaschinen in der vormodernen Psychiatrie. In: Schönhammer R. editor. Körper, Dinge Und Bewegung. Der Gleichgewichtssinn in Mate- rieller Kultur Und Ästhetik. Wien, Austria: Facultas; 2009:128-139.

4. Cox JM. Practical observations on insanity. 2nd ed. London: Baldwin; 1806.

5. Breathnach CS. Hallaran's circulating swing. Hist Psychiatry. 2010;21(81 Pt 1):79-84. 
6. Galvani L. De Viribus Electricitatis in Motu Musculari Commentarius. Institute of Sciences at Bologna, Bologna.1791.

7. Bárány R. Physiologie und Pathologie (Funktions-Prufung) des Bogengang-Apparates beim Menschen. Germany: Deuticke F Leipzig; 1907.

8. Devi NP, Mukkadan JK. Effect of rotatory vestibular stimulation on learning and memory in rats-standardization of a novel method. Int $J$ Pharm Pharm Sci. 2016;9(1):145-151.

9. Smitha KK, Dinesh KS, Mukkadan JK. Standardisation of controlled vestibular stimulation for optimal stress relief in albino wistar rats. The Pharma Innovation Journal. 2015;4(2):01-03.

10. Houpt TA, Pittman DW, Barranco JM, et al. Behavioral effects of highstrength static magnetic fields on rats. J Neurosci. 2003;23(4):14981505 .

11. Bec JM, Albert ES, Marc I, et al. Characteristics of laser stimulation by near infrared pulses of retinal and vestibular primary neurons. Lasers Surg Med. 2014;44(9):736-745.

12. Stackman RW, Taube JS. Firing properties of head direction cells in the rat anterior thalamic nucleus: dependence on vestibular input. J Neurosc. 1997;17(11):4349-4358.
13. Stackman RW, Clark AS, Taube JS. Hippocampal spatial representations require vestibular input. Hippocampus. 2002;12(3):291-303.

14. Russel NA, Horii A, Smith PF. The long-term effects of permanent vestibular lesions on hippocampal spatial firing. $J$ Neurosci. 2003;23(16):6490-6498.

15. Shinder, ME, Taube JS. Differentiating ascending vestibular path- ways to the cortex involved in spatial cognition. J Vestib Res. 2010;20(1):3-23.

16. Brandt T, Schautzer F, Hamilton DA, et al. Vestibular loss causes hippocampal atrophy and impaired spatial memory in humans. Brain. 2005;128(Pt 11):2732-2741.

17. Tai SK, Leung LS. Vestibular stimulation enhances hippocampal longterm potentiation via activation of cholinergic septohippocampal cells. Behav Brain Res. 2012;232(1):174-182.

18. Sailesh KS, Mukkadan JK. Vestibular modulation of endocrine secretions-A review. Int J Res Health Sci. 2014;2(1).

19. Devi NP, Mukkadan JK. Impact of rotatory vestibular stimulation and Myristica fragrans on spatial learning and memory in wistar albino rats. JIPBS. 2016;3(1):017-032.

20. Kumar Sai Sailesh, Archana R, Mukkadan JK. Thinking with your sixth sense. RJPBCS. 2014;5(4):481-485. 